\title{
Evaluation of Brain Volume Loss in Different Clinical Types of Multiple Sclerosis Patients
}

\author{
MUSTAFA M. HASHEM, M.Sc.*; TAREK A. RAGEH, M.D.*; AMR F. MOURAD, M.D.** and \\ HASSAN M. FARWEEZ, M.D.* \\ The Departments of Neurology \& Psychiatry* and Radiology**, Faculty of Medicine, Assiut University, Assiut, Egypt
}

\begin{abstract}
Background: Brain atrophy is an important imaging biomarker in predicting future disability and progression of disease in multiple sclerosis.

Aim of Study: We need to evaluate brain volume loss in different clinical types of MS and correlates it with physical disability using NeuroQuaqnt 2.0 automated volumetric measurement of brain atrophy in MS.
\end{abstract}

Material and Methods: We conducted the following study on 40 MS patients (4 CIS, 8 PPMS, 22 RRMS and 6 SPMS) for clinical evaluation, assessment their physical disability by (EDSS) and automated volumetric measurement of 3 parameters (whole brain, lateral ventricles and thalami volumes) by obtain 3D T1 non contrast, saggital MRI scan by using new software (NeuroQuant ${ }^{\circledR 2} 2.0$ automated volumetric measurement of brain atrophy) of MS patients.

Results: Thalami atrophy was predominant atrophy in 24 patients. Also, it was predominant atrophy in different clinical types (2 CIS, 4 PPMS, 12 RRMS and 6 SPMS) patients. Morphometry results were correlated with physical disability (whole brain volume $r=0.400, p=0.026$ ), (thalami volume $r=0.379, p=0.016$ ), and (lateral ventricles volume $r=0.365, p=0.044$ ). MS patients with (disease duration $>1$ year) had significant lower whole brain volume $(p=0.037)$, lower thalami volume $(p=0.019)$ and higher lateral ventricles volumes $(p=0.044)$.

Conclusion: Thalami atrophy is a predominant atrophy in different clinical types of MS patients. Thalami atrophy may be used a sole indices in brain atrophy measuring. Brain atrophy correlates with physical disability and progress with duration of illness.

Key Words: Multiple sclerosis - Brain atrophy-Volumertic MRI.

\section{Introduction}

MULTIPLE Sclerosis (MS) is one of the most common neurological disorders and a leading cause

Correspondence to: Dr. Mustafa M. Hashem, The Department of Neurology \& Psychiatry, Faculty of Medicine,

Assiut University, Assiut, Egypt of non traumatic disability in young adults in many countries. Previous reports from the Middle East and North Africa have suggested a moderate to high risk of MS in these countries [1].

The loss of brain volume, or brain atrophy in MS, has been classically considered as a marker present in severe or advanced stages of the disease [2]. However, previous studies have demonstrated that this phenomenon also occurs in patients with clinically isolated syndromes suggestive of MS [3] and also in the radiologically isolated syndrome [4]. Brain atrophy in MS can predict future progression of physical and cognitive disability [5-8] .

Nowadays, brain atrophy in MS constitutes a major part in clinical researches for prediction physical disability and monitoring efficacy of treatment [9]. There are many automated techniques for measurement brain atrophy in MS such as SIENA(X) [10], MSmetrixTM (IcoMetrix) and

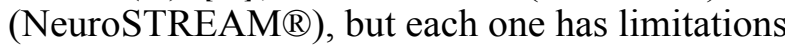
in its application.

One of the most recent automated radiological techniques in measurement brain atrophy in MS is NeuroQuaqnt 2.0 automated volumetric measurement of brain atrophy in MS. (www. wholebrainatrophy.com).

As studying of brain atrophy in MS using automated techniques are lacking in Egypt and Arab countries, our study aim to analyze brain atrophy among multiple sclerosis patients and in its different clinical types (whether occur early (CIS and RRMS or late (PPMS and SPMS). Also, studying the impact of brain atrophy on disease progression and physical disability of MS patients by using NeuroQuaqnt 2.0 automated volumetric measurement of brain atrophy in MS. (www.wholebrainatrophy. com). 


\section{Material and Methods}

The current study was across sectional, hospital based study, conducted in Neurology Unit, Neuropsychiatry Hospital, Assiut University, Egypt between the 1 st of October 2015 and the 30 th of September 2016. The Assiut University Medical Ethical Review Board approved the study.

Our study included two groups. First group included patients diagnosed as multiple sclerosis according to revised MacDonald's criteria 2010 [11] or CIS patients highly suggestive of MS. We included both sexes, aged 18-50 years and their EDSS [12] score (1-7). We excluded patients with History or current evidence of CNS diseases other than MS which may affect brain volume e.g (Dementia, parkinsonism, other inflammatory CNS diseases) and those with relapse or took steroid within previous one month from examination.

Patients included in our study period were 40 patients, they were 21 females \& 19 males, their mean age \pm SD $32.73 \pm 9.90$ and subjected to history taking, full general and neurological examination, laboratory tests included (CBC, screening tests included (antinuclear Abs, antidouble stand DNA, RF), to exclude other diseases mimic MS, their physical disability assessed by EDSS score [12], MRI brain and spinal cord helped to confirm diagnosis of MS and brain volume loss assessed by (NeuroQuant ${ }^{\circledR 2.0}$ automated volumetric measurement of brain atrophy): (www.wholebrainatrophy. $\underline{\text { com). }}$.

NeuroQuant ${ }^{\circledR} 2.0$ automated volumetric measurement of brain atrophy): (www. wholebrainatrophy.com) is a new medical software automatically identifies and quantifies the volumes of brain structures, also provides supportive evidence of brain volume loss in MS. NeuroQuant ${ }^{\circledR} 2.0$ is a Food and Drug Administration (FDA) approved and CE (European Conformity) marked fullyautomated implementation that computes crosssectional regional and global brain volumes on high-resolution 3DT1-WI, NeuroQuant compares the brain volumes to a normative database adjusted for age, gender and intracranial volume [13].

Advantages of using NeuroQuant ${ }^{\circledR 2} 2.0$ automated volumetric measurement of brain atrophy with dynamic atlas approach in MS included fully automated, more accurate and reliable method of measuring brain atrophy, fast method (it takes 57 minutes). It measures global and regional brain atrophy at the same time [it gives 3 measures at one report whole brain, lateral ventricles and thalami volumes at the same report].
In our study we used (NeuroQuant ${ }^{\circledR 2.0}$ whole brain atrophy report) to assess: (Whole brain volume, lateral ventricles and thalami volumes) according to NeuroQuant 2.0 MRI protocol and analysis.

\section{MRI scan acquisition:}

All MS patients received MR scan obtained by using (1.5 T siemens Era machine 24 channels, Germany). The following sequence were obtained for MS subjects (saggital T1-weighted mprage fast 3D structural non contrast MRI sequence).

The details of pulse sequence included Field of View (FOV) 240 X $256 \mathrm{~mm}$, fov phase $100 \%$, slice thickness $1.2 \mathrm{~mm}$, number of slices 160-170, repetitive time (TR) $2400 \mathrm{~ms}$, echo time (TE) minimum, TI $1000 \mathrm{~ms}$, flipe angle 8 degree, band width 180HZ/pix, Echo spacing 7.3ms.

Image processing: (NeuroQuant 2.0 automated brain image analysis):

MRI Images were transferred to (network of cortechs labs, Inc. Sandiago CA USA) by using medical software NeuroQuant automated brain image analysis. It was taking quantifiable volumetric image segmentation by using "dynamic atlas" [14]. Dynamic atlas(the new personalized segmentation approach), is the unique and innovative atlas and considered as a core functionality of latest version of NeuroQuant 2.0.

NeuroQuant uses dynamic atlas based segmentation approach. By using dynamic atlas, MRI images of our studied MS patients were automatically matched with parameters of MRI images of healthy individuals who extensively represented in this atlas (as matched for age, gender but more accuracy with their birth dates), so we got more accurate results than using static atlas. The dynamic Atlas framework generalizes the multi-static atlas approach to a continuous range over any arbitrary number of covariates (e.g. age and gender) by applying a continuous statistical model as a prediction engine.

Prior to fitting the model, data were inspected to ensure quality of initial segmentation and registration with atlas. Those subjects that did not meet the stringent quality criteria were discarded from further analysis. Then the model fitted to the observed data, which included both the original image data and derived data (e.g. registration and segmentation parameters), using smooth functions of the predictor variables. In this way, any particular combination of covariate values that makes up an individual (e.g. age, gender) can then be used to 
predict the atlas parameters that are appropriate for that individual.

After that the dynamic Atlas could generate a custom target image, class likelihoods, and class priors in a principled model-based approach specific to each individual. The procedure for creating the dynamic Atlas is shown in Fig. (1).

So, our second group was automated healthy individuals who represented on dynamic atlas of NeuroQuant 2.0 for matching with age and sex of studied MS patients. From this automated method we did not need for taking control group as our radiological method for assessment brain volume loss was automated comparison with healthy individuals.

Our morphometry results of whole brain atrophy report (whole brain, lateral ventricles and thalami volumes) detected by normative percentile (5\%$95 \%$ ) and volume $\mathrm{cm}^{3}$. Fig. (2).

All patients included in the study signed a written informed consent before participation.

\section{Statistical analysis:}

Date entry and data analysis were done using SPSS Chicago, IL, USA, Version 19 (Statistical Package for Social Science). Data were presented as number, percentage, mean, standard deviation. Mann-Whitney test was used to compare quantitative variables between two groups and Kruskal Wallis Test for more than two groups in case of non-parametric data. Spearman correlation was done to measure correlation between quantitative variables. $p$-value considered statistically significant when $p<0.05$.

\section{Results}

Demographic and clinical characteristics of different clinical phenotypes of MS patients (Table 1):

Our results showed that there was statistical significant difference between different clinical phenotypes of MS patients as regard duration of illness (years) and physical disability detected by EDSS as shown in (Table 1).

Table (1): Demographic and clinical characteristics of different clinical phenotypes of MS patients.

\begin{tabular}{|c|c|c|c|c|c|}
\hline \multirow[b]{2}{*}{ Characteristics } & \multicolumn{4}{|c|}{ Clinical types of MS } & \multirow{2}{*}{$\begin{array}{c}p- \\
\text { value }\end{array}$} \\
\hline & $\begin{array}{c}\text { CIS }(n=4) \\
\text { Mean } \pm S D\end{array}$ & $\begin{array}{l}\text { PPMS }(n=8) \\
\text { Mean } \pm S D\end{array}$ & $\begin{array}{c}\text { RRMS }(n=22) \\
\text { Mean } \pm S D\end{array}$ & $\begin{array}{l}\text { SPMS }(n=6) \\
\text { Mean } \pm S D\end{array}$ & \\
\hline Age (years) & $27.00 \pm 14.10$ & $35.25 \pm 10.01$ & $32.50 \pm 9.88$ & $34.00 \pm 7.51$ & 0.540 \\
\hline $\operatorname{Sex}(m / f)$ & $4 / 0$ & $5 / 3$ & $9 / 13$ & $1 / 5$ & 0.097 \\
\hline Age at onset (years) & $27.50 \pm 13.80$ & $32.62 \pm 9.80$ & $30.50 \pm 9.79$ & $30.33 \pm 7.74$ & 0.823 \\
\hline Duration of disease (years) & $0.11 \pm 0.08$ & $2.64 \pm 1.98$ & $2.13 \pm 4.44$ & $3.58 \pm 2.84$ & $0.013 *$ \\
\hline Total EDSS & $1.75 \pm 0.96$ & $6.13 \pm 1.27$ & $3.00 \pm 2.22$ & $6.25 \pm 0.61$ & $0.000 *$ \\
\hline $\begin{array}{ll}* & \text { : Statistical significant d } \\
\text { CIS } & \text { : Clinical Isolated Syndr } \\
\text { PPMS } & \text { : Primary Progressive M } \\
\text { RRMS } & \text { : Relapsing Remitting M } \\
\text { SPMS } & \text { : Secondary Progressive } \\
\text { EDSS } & \text { : Expanded Disability St } \\
\text { All data are presented as n, or }\end{array}$ & $\begin{array}{l}\text { fference }(p<0.05 \\
\text { me. } \\
\text { dtiple Sclerosis. } \\
\text { ultiple Sclerosis. } \\
\text { Multiple Sclerosi } \\
\text { atus Scale. }\end{array}$ & ation & & & \\
\hline
\end{tabular}

Morphometry results (whole brain, lateral ventricles and thalami volumes) of MS patients:

Our results showed that predominant atrophy in MS patients was thalami atrophy in 24 patients $(60.0 \%)$ then whole brain atrophy and lateral ventricles dilatation in 21 patients $(52.5 \%)$ as compared with healthy individuals who automated represented in dynamic atlas.

Analysis of morphometry results in different clinical phenotypes in MS patients (Table 2):

Also, our results showed that thalami atrophy was predominant atrophy in different clinical phe- notypes of MS patients in 6 SPMS patients (100.0\%), 12 RRMS patients $(54.5 \%), 4$ PPMS $(50.0 \%)$ and 2 CIS patients $(50.0 \%)$ (Table 2 ).

As regard analysis of brain volume loss in CIS and RRMS patients:

Our results showed that whole brain atrophy, thalami atrophy and lateral ventricles dilatation occurred in 2 of 4 CIS patients $(50.0 \%)$. Also, thalami atrophy occurred in 12 patients of 22 RRMS patients (54.5\%), whole brain atrophy in 10 patients $(45.5 \%)$ and lateral ventricles dilatation in 11 patients $(50.0 \%)$, all these patients had disease duration ( $<24$ months). 
Table (2): Percentage of morphometry results (whole brain atrophy, lateral ventricles dilatation \& thalami atrophy) detected by normative percentile among clinical types of studied multiple sclerosis patients.

\begin{tabular}{lcccccccccc}
\hline \multirow{2}{*}{ Percentile } & \multicolumn{2}{c}{ CIS (n=4) } & \multicolumn{2}{c}{ PPMS $(\mathrm{n}=8)$} & \multicolumn{2}{c}{ RRMS $(\mathrm{n}=22)$} & \multicolumn{2}{c}{ SPMS (n=6) } & \multicolumn{2}{c}{ Total (n=40) } \\
\cline { 2 - 11 } & No. & $\%$ & No. & $\%$ & No. & $\%$ & No. & $\%$ & No. & $\%$ \\
\hline Whole brain atrophy & 2 & 50.0 & 3 & 37.5 & 10 & 45.5 & 6 & 100.0 & 21 & 52.5 \\
Lateral ventricles dilatation & 2 & 50.0 & 3 & 37.5 & 11 & 50.0 & 5 & 83.3 & 21 & 52.5 \\
Thalami atrophy & 2 & 50.0 & 4 & 50.0 & 12 & 54.5 & 6 & 100.0 & 24 & 60.0 \\
\hline
\end{tabular}

CIS : Clinical Isolated Syndrome.

PPMS : Primary Progressive Multiple Sclerosis.

RRMS : Relapsing Remitting Multiple Sclerosis.

SPMS: Secondary Progressive Multiple Sclerosis.

All data are presented as n (\%).

Correlation of brain volume loss with physical disability of studied MS patients: (Table 3):

Our results demonstrated that there was a significant negative correlation between whole brain volume, thalami volume with physical disability (detected by EDSS), also there was a significant positive correlation between lateral ventricles volume and physical disability of studied MS patients.

Comparing morphometry results among duration of illness (years) in studied MS patients: (Table 4):

In our study, we divided MS patients into two groups, group A (disease duration $<1$ year, $n=17$ ) and group $B$ (disease duration $>1$ year, $n=23$ ) in order to assess brain volume loss with progression of disease.

There was stastistical significant lower morphometry results as regard whole brain and thalami volumes in group B (disease duration $>1$ year, $\mathrm{n}=23$ ) and increased lateral ventricles volume in that group.
Table (3): Correlation of brain volume loss with physical disability of studied MS patients.

\begin{tabular}{lcc}
\hline \multirow{2}{*}{ Morphometry } & \multicolumn{2}{c}{ EDSS } \\
\cline { 2 - 3 } & $r$-value & $p$-value \\
\hline Whole brain volume & -0.400 & $0.026^{*}$ \\
Lateral ventricles volume & 0.365 & $0.044^{*}$ \\
Thalami volume & -0.379 & $0.016^{*}$ \\
\hline
\end{tabular}

- Spearman correlation was done to estimate relationship between morphometry results and physical disability (EDSS).

$*$ : Statistical significant difference $(p<0.05)$.

EDSS: Expanded Disability Status Scale.

Table (4): Comparing morphometry results among duration of illness (years) in studied MS patients.

\begin{tabular}{llll}
\hline \multirow{2}{*}{ Morphometry } & \multicolumn{2}{c}{ Duration of illness (years) } & \\
\cline { 2 - 3 } & $\begin{array}{c}<1 \text { year }(\mathrm{n}=17) \\
\text { (group A) } \\
\text { Mean } \pm \text { SD }\end{array}$ & $\begin{array}{c}\geq 1 \text { year }(\mathrm{n}=23) \\
\text { (group B) } \\
\text { Mean } \pm \text { SD }\end{array}$ & $\begin{array}{c}p \text { value } \\
\text { vean }\end{array}$ \\
\hline $\begin{array}{l}\text { Whole brain } \\
\text { volume }\end{array}$ & $1250.32 \pm 168.27$ & $1121.08 \pm 184.29$ & $0.037^{*}$ \\
$\begin{array}{c}\text { Lateral ventricles } \\
\text { volume }\end{array}$ & $33.07 \pm 17.10$ & $45.92 \pm 19.82$ & $0.044^{*}$ \\
Thalami volume & $14.43 \pm 3.58$ & $10.75 \pm 2.80$ & $0.019^{*}$ \\
\hline
\end{tabular}

*: Statistical significant difference $(p<0.05)$.

All data are presented mean \pm standard deviation.

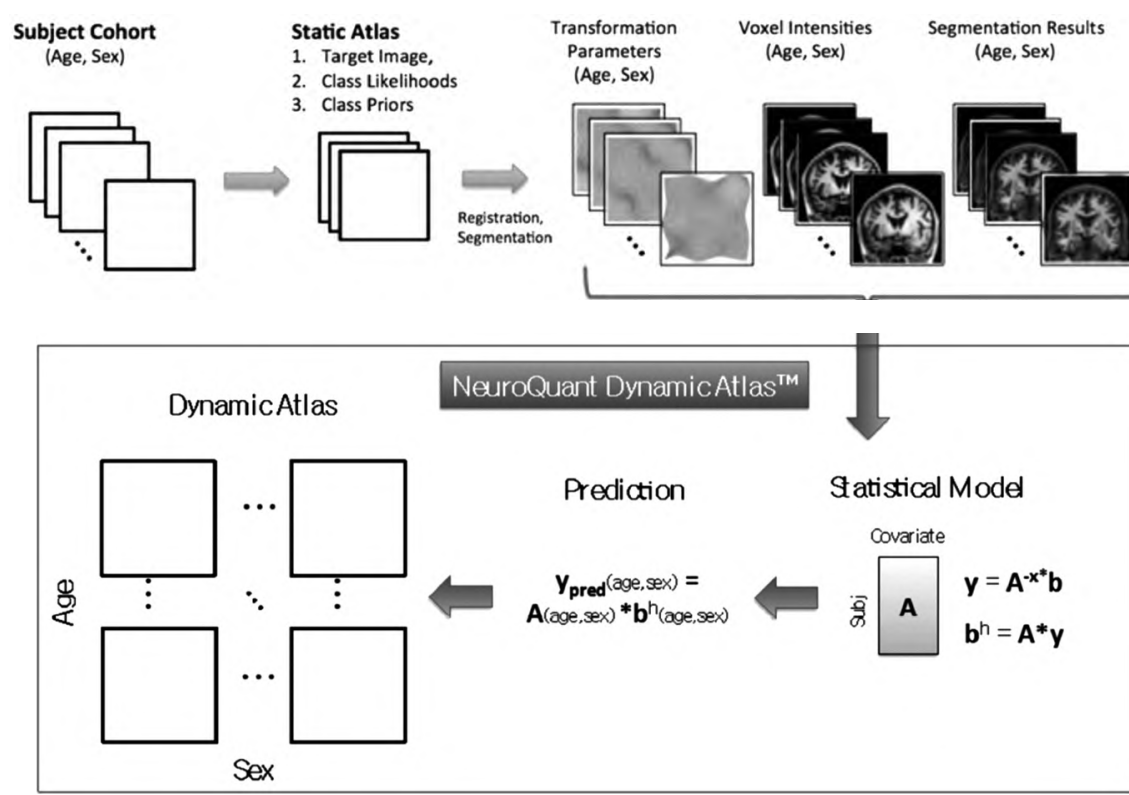

Fig. (1): Creation of the dynamic Atlas using age and gender as predictors (covariates). 

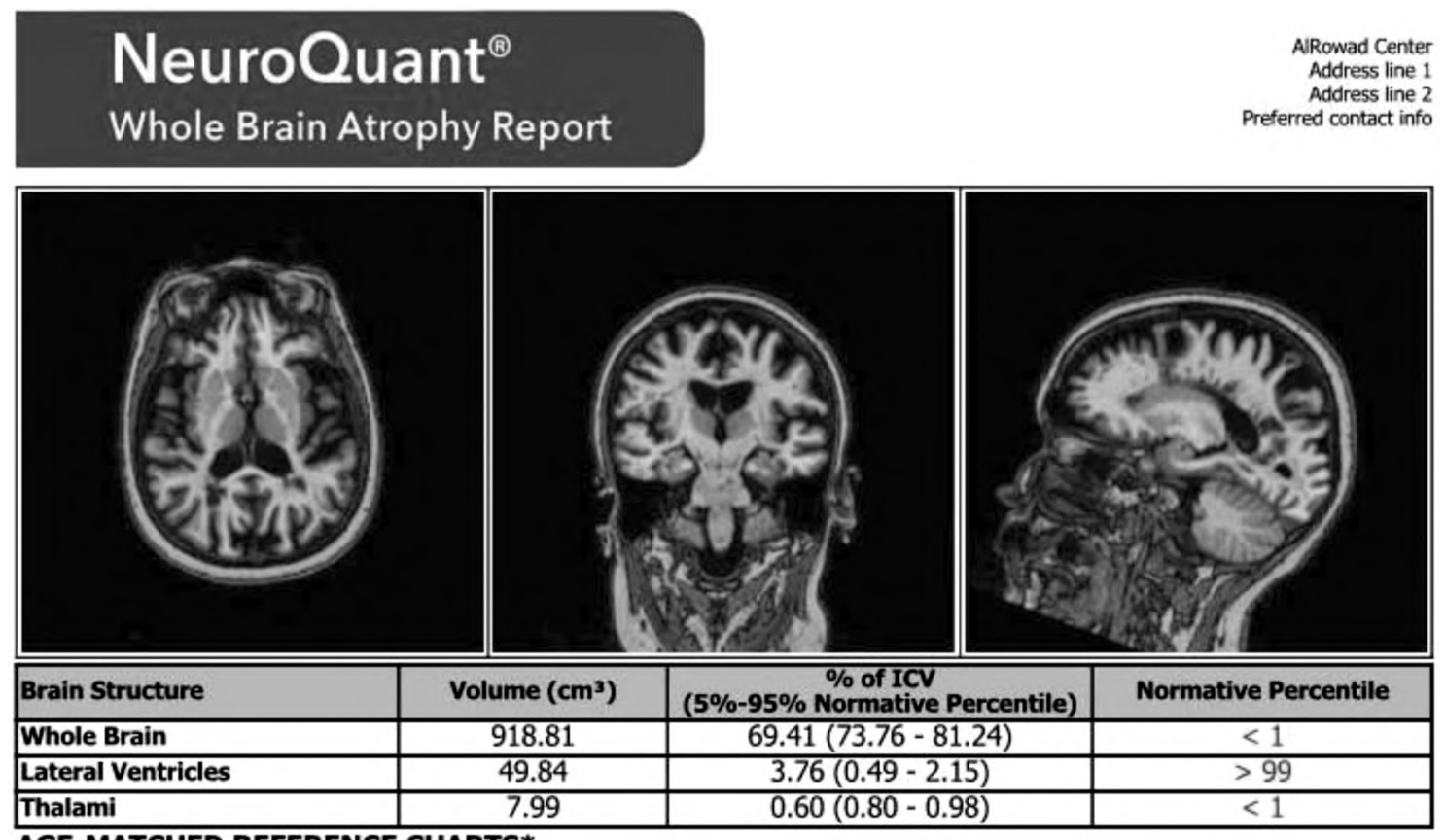

AGE-MATCHED REFERENCE CHARTS*
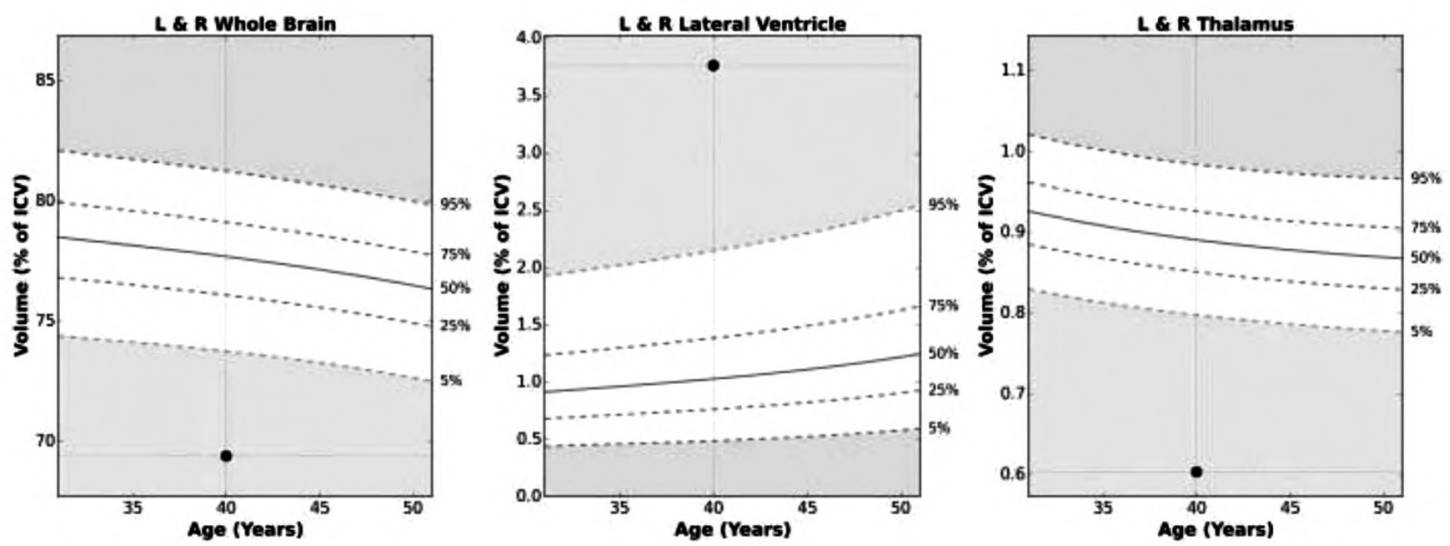

Fig. (2): Fully automated segmentations performed by NeuroQuant ${ }^{\circledR} 2.0$. shows whole brain atrophy report of MS patient in the form of reduced whole brain volume, thalami volume and increased lateral ventricles volume, as comparison with age and sex matched reference chart, normative percentile (5\%-95\%).

\section{Discussion}

Nowadays, brain atrophy and its measurement in multiple sclerosis represents a major constituting part in clinical researches either in predicting future disability or monitoring efficacy of treatment.

Up to your knowledge, we are the first study in Egypt and Arab countries used automated cross sectional segmentation based technique for measurement brain volume loss in multiple sclerosis patients (NeuroQuant 2.0 automated volumetric measurement of brain atrophy using dynamic atlas approach).

The present study demonstrated that predominant atrophy was thalami atrophy in 24 (60.05) studied MS patients, which was in a line with several previous studies [15-17], but our results were higher than previously published data of $17 \%$ to $25 \%$ thalami atrophy in MS patients [15-16]. This could be explained by we used new method for measurement brain atrophy and early detection of thalami atrophy among different clinical types of MS patients.

The current study showed that criteria of brain and thalami atrophy varied with different clinical types of MS patients. In our study, those with secondary progressive MS type had higher percentage of whole brain atrophy in 6 patients $(100.0 \%)$, thalami atrophy in 6 patients $(100.0 \%)$ and lateral ventricles dilatation in 5 patients $(83.3 \%)$ than any 
other clinical types of MS patients. This was consistent with Benedict et al., 2006 [18] who reported that patients with SPMS type showed more whole brain atrophy and lateral ventricles dilatation than those with RRMS type.

We could be explained that, in our study SPMS patients had mean disease longer than any other types of MS patients. So, we reasoned that disease duration may be a major contributing factor for brain volume loss in MS patients.

Interestingly in current study, CIS and RRMS patients with disease duration ( $<2$ years) had whole brain, thalami atrophy and lateral ventricles dilatation. As regard whole brain atrophy in 2 CIS patients $(50 \%)$ was consistent with data reported by $[3,19]$. Although there were various reports in the literature describing the phenomenon of early brain atrophy in patients with MS [20-22] there have been few studies to date that assess the phenomenon of atrophy at the time of CIS.

Regarding thalami atrophy in CIS and RRMS patients $(50.0 \%, 54.0 \%)$ of studied patients respectivley, our findings were consistent with data reported by [23], moreover in present study we founded thalami atrophy early in CIS patients with disease duration less than $<24$ months. This was also in agreement with Deppe et al., [23]. Previous study explained early thalamic atrophy in patients with CIS and RRMS was mainly caused by silent microstructural destructive processes within the thalamus and not only by retrograde neuroaxonal degeneration or anterograde transsynaptic changes secondary to WM lesions by means of volumetry as performed on 3D datasets or by DTI [23] .

Also, the current study demonstrated that there was a significant correlation between morphometry results and physical disability(determined by EDSS) of MS patients, (whole brain volume $r=-0.400, p$ $=0.026$ ) which was in a line with previously published data reported by $[\mathbf{2 4 , 2 5 ]}$ who reported that there was an association between brain volume loss and disability progression as well as worsening disability over along duration of time.

The present study demonstrated that there was a significant negative correlation between thalami volume and and physical disability of MS patients ( $r=-0.379, p=0.016)$, which was consistent with [26,27]. On the other hand, Davies et al., 2005 [28] demonstrated that there was no correlation between thalami volume and EDSS explained as EDSS is heavily biased toward motor performance and anatomically thalamic role in motor involvement is mainly functional modulator [28]. Therefore, thalami atrophy is less related to physical disability in MS.

We agree with data showed that there was a correlation between thalami volume and and physical disability of MS patients. We explained this as using new method of radiological measurement of thalamus atrophy, large sample size and followup of thalamic measurement and its correlation with physical disability over many years. All these measures gave robustness of these studies.

In current study, we need to evaluate impact of duration of illness on morphometry results. We founded that brain atrophy progress with duration of illness evident by presence of significant lower whole brain and thalami volumes $(p=0.037, p=$ 0.019 ) in MS patients with duration of illness $>1$ year, which was consistent with data published by $[23,24,26]$

The strengths of our study include that it was fully automated radiological method of measuring brain atrophy in MS patients, accurate, fasting (57 minutes), reducing cost and used whole brain atrophy report which gives three parameters at the same report (whole brain, lateral ventricles, thalami volumes). Finally, we studied different clinical types of MS patients.

The study had its limitations including that it was cross sectional, but we used an accurate fully automated cross sectional segmentation approach. Second limitation of our study was small sample size, but we depend on calculated sample size of our hospital based study.

In conclusion, evaluation of brain trophy varies in MS patients and in its different clinical types. Thalami atrophy was predominant atrophy in MS patients and its different clinical types. Brain atrophy progress with duration of illness and correlates with physical disability of MS patients. Further studies are needed to evaluate brain trophy with different automated radiological techniques in NAWM and NAGM, correlate it with different cognitive domains of MS patients.

\section{References}

1- HEYDARPOUR P., et al.: Multiple Sclerosis Epidemiology in Middle East and North Africa: A Systematic Review and Meta-Analysis. Neuroepidemiology, 44 (4): p. 23244, 2015.

2- FILIPPI M. and F. AGOSTA: Imaging biomarkers in multiple sclerosis. J. Magn. Reson. Imaging, 31 (4): p. $770-88,2010$ 
3- PEREZ-MIRALLES F., et al.: Clinical impact of early brain atrophy in clinically isolated syndromes. Mult. Scler., 19 (14): p. 1878-86, 2013.

4- ROJAS J.I., et al.: Brain atrophy in radiologically isolated syndromes. J. Neuroimaging., 25 (1): p. 68-71,2015.

5- FISHER E., et al.: Gray matter atrophy in multiple sclerosis: A longitudinal study. Annals of Neurology, 64 (3): p. 255-65, 2008.

6- POPESCU V., et al.: Brain atrophy and lesion load predict long term disability in multiple sclerosis. J. Neurol. Neurosurg. Psychiatry, 84 (10): p. 1082-91, 2013.

7- UHER T., et al.: Longitudinal MRI and neuropsychological assessment of patients with clinically isolated syndrome. J. Neurol., 261 (9): p. 1735-44, 2014.

8- ZIVADINOV R., et al.: A serial 10-year follow-up study of brain atrophy and disability progression in RRMS patients. Mult. Scler., 22 (13): p. 1709-18, 2016.

9- ZIVADINOV R., et al.: Clinical relevance of brain atrophy assessment in multiple sclerosis. Implications for its use in a clinical routine. Expert. Rev. Neurother., 16 (7): p. 777-93, 2016.

10- SMITH S.M., et al.: Accurate, robust, and automated longitudinal and cross-sectional brain change analysis. Neuroimage, 17 (1): p. 479-89, 2002.

11- POLMAN C.H., et al.: Diagnostic criteria for multiple sclerosis: 2010 revisions to the McDonald criteria. Ann. Neurol., 69 (2): p. 292-302, 2011.

12-KURTZKE J.F.: Rating neurologic impairment in multiple sclerosis: An expanded disability status scale (EDSS). Neurology, 33 (11): p. 1444-52, 1983.

13-WANG C., et al.: Automated brain volumetrics in multiple sclerosis: A step closer to clinical application. J. Neurol. Neurosurg. Psychiatry, 87 (7): p. 754-7, 2016.

14- CorTechsLabswhite paper"DynamicAtlas". http://www. . cortechslabs. com/whitepapers/).

15-CIFELLI A., et al.: Thalamic neurodegeneration in multiple sclerosis. Ann. Neurol., 52 (5): p. 650-3, 2002.

16- WYLEZINSKA M., et al.: Thalamic neurodegeneration in relapsing-remitting multiple sclerosis. Neurology, 60 (12): p. 1949-54, 2003.

17- HOUTCHENS M.K., et al.: Thalamic atrophy and cognition in multiple sclerosis. Neurology, 69 (12): p. 121323, 2007.

18- BENEDICT R.H., et al.: Neocortical atrophy, third ventricular width, and cognitive dysfunction in multiple sclerosis. Arch. Neurol., 63 (9): p. 1301-6, 2006.

19- ROJAS J.I., et al.: [Brain atrophy in clinically isolated syndrome]. Neurologia, 25 (7): p. 430-4, 2010.

20- KIDD D., et al.: Cortical lesions in multiple sclerosis. Brain, 122 ( Pt 1): p. 17-26, 1999.

21- PETERSON J.W., et al.: Transected neurites, apoptotic neurons, and reduced inflammation in cortical multiple sclerosis lesions. Ann. Neurol., 50 (3): p. 389-400, 2001.

22- De STEFANO N.E.A.: Evidence of early cortical atrophy in MS: Relevance to white matter changes and disability. Neurology, 60: p. 1157-62, 2003.

23- DEPPE M., et al.: Early silent microstructural degeneration and atrophy of the thalamocortical network in multiple sclerosis. Hum. Brain Mapp., 37 (5): p. 1866-79, 2016.

24- RADUE E.W., et al.: Correlation between brain volume loss and clinical and MRI outcomes in multiple sclerosis. Neurology, 84 (8): p. 784-93, 2015.

25- JEFFERY D.R., et al.: The relationship between the rate of brain volume loss during first 24 months and disability progression over 24 and 48 months in relapsing MS. J. Neurol., 263 (2): p. 299-305, 2016.

26- ROCCA M.A., et al.: Thalamic damage and long-term progression of disability in multiple sclerosis. Radiology, 257 (2): p. 463-9, 2010.

27- ZIVADINOV R., et al.: Evolution of cortical and thalamus atrophy and disability progression in early relapsing remitting MS during 5 years. A.J.N.R. Am. J. Neuroradiol., 34 (10): p. 1931-9, 2010.

28- DAVIES G.R., et al.: Emergence of thalamic magnetization transfer ratio abnormality in early relapsing-remitting multiple sclerosis. Mult. Scler., 11 (3): p. 276-81, 2005. 


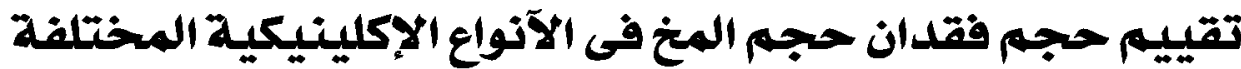

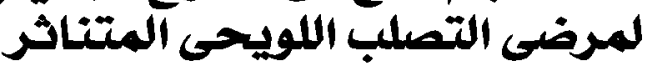

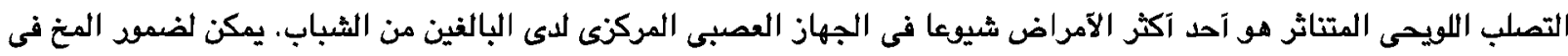
مرض التصلب اللويحى المتناثر التبؤ بالتقدم المستقبلى لإلإعاقة البدنية والمعرفية.

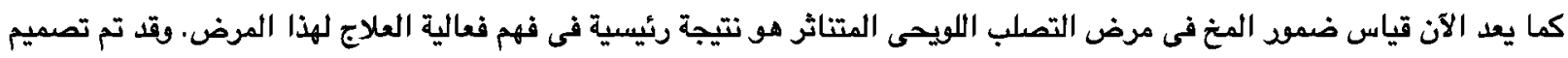

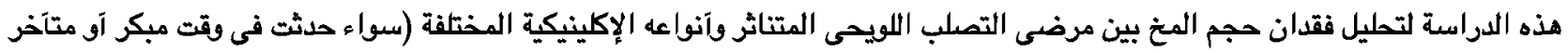

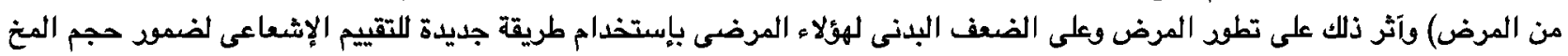

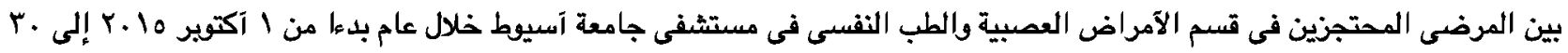

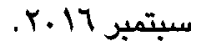
وقد آجرى لجميع المرضى الذين يعانون من مرض التصلب اللويحى المتاثر فى هذه الدراسة:

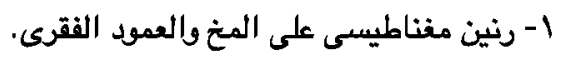

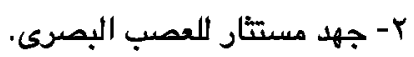

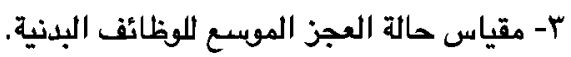
ع- التقييم الإشعاعى لضمود المخ بإستخدام (القياس الحجمى الآلى لضمو المخائ). كما تلخصت نتائج هذا العمل في الآتى:

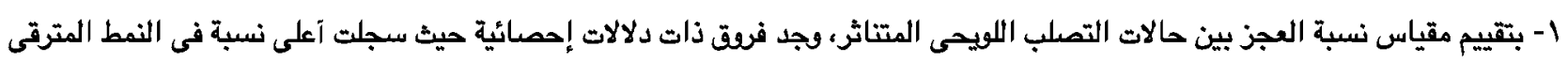

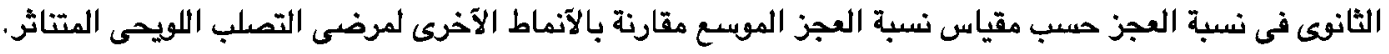
ץ- كما وجد فرقق ذات دلالة إحصائية بين الآنواع المختلفة لمرضى التصلب اللويحى المتناثر من حيث مدة المرض، حيث كانت آعلى نسبة لمرضى التصلب اللويحى المتناثر المترقى الثانوى دئ.

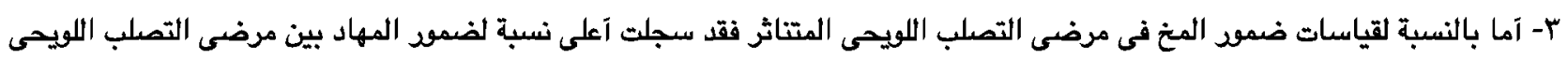

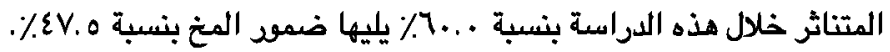

ع - كما سجلت آيضا آعلى نسبة لضمور المهاد بين الآنواع المختلفة لمرضى التصلب اللويحى المتناثر. ه- وجدت ايضا علاقة بين قياسات ضمود المخ وضمور الههاد في مرضى التصلب اللويحى المتناثر مع قياس حالة العجز الموسع. 